\title{
The autophagic response to polystyrene nanoparticles is mediated by transcription factor EB and depends on surface charge
}

\author{
Wensi Song ${ }^{1}$, Lauren Popp ${ }^{1}$, Justin Yang ${ }^{1}$, Ayushi Kumar ${ }^{1}$, Varun Shenoy Gangoli ${ }^{1}$ and Laura Segatori ${ }^{1,2,3^{*}}$
}

\begin{abstract}
Background: A number of engineered nanoparticles induce autophagy, the main catabolic pathway that regulates bulk degradation of cytoplasmic material by the lysosomes. Depending on the specific physico-chemical properties of the nanomaterial, however, nanoparticle-induced autophagy may have different effects on cell physiology, ranging from enhanced autophagic degradation to blockage of autophagic flux. To investigate the molecular mechanisms underlying the impact of nanoparticle charge on the nature of the autophagic response, we tested polystyrene nanoparticles $(50 \mathrm{~nm})$ with neutral, anionic, and cationic surface charges.

Results: We found all polystyrene nanoparticles investigated in this study to activate autophagy. We showed that internalization of polystyrene nanoparticles results in activation of the transcription factor EB, a master regulator of autophagy and lysosome biogenesis. Autophagic clearance, however, was observed to depend specifically on the charge of the nanoparticles. Particularly, we found that the autophagic response to polystyrene nanoparticles presenting a neutral or anionic surface involves enhanced clearance of autophagic cargo. Cell exposure to polystyrene nanoparticles presenting a cationic surface, on the other hand, results in transcriptional upregulation of the pathway, but also causes lysosomal dysfunction, ultimately resulting in blockage of autophagic flux.
\end{abstract}

Conclusions: This study furthers our understanding of the molecular mechanisms that regulate the autophagic response to nanoparticles, thus contributing essential design criteria for engineering benign nanomaterials.

Keywords: Autophagy, Lipopigment, Lysosome, Nanoparticle, Transcription factor EB (TFEB)

\section{Background}

Engineered nanoparticles are widely explored for a variety of biomedical applications, including drug delivery $[1-3]$, in vitro and in vivo diagnostics $[4,5]$, and production of biocompatible materials [6,7]. Because of their unique physical and chemical properties, nanoparticles interact with biological components and systems, which also operate at the nanoscale. As a result, nanoparticles induce a variety of biological responses [8-16] including autophagy [17-21], the main catabolic pathway that mediates degradation of aggregated proteins, damaged organelles, and pathogens by lysosomes [22].

\footnotetext{
*Correspondence: segatori@rice.edu

${ }^{1}$ Department of Chemical and Biomolecular Engineering, Rice University, Houston, TX 77005, USA

Full list of author information is available at the end of the article
}

Markers of autophagy have been detected upon cellular uptake of a variety of engineered nanoparticles, including metal oxide nanoparticles $[23,24]$, quantum dots [19, 25], fullerenes [21, 26], gold nanoparticles [18, 27], silver nanoparticles [28], and polymeric nanoparticles [29]. While autophagy is generally considered a pro-survival pathway [30-32], activation of autophagy has also been observed in association with cell death, suggesting that autophagy may play a role in the mechanism of nanoparticle-induced toxicity [33]. However, the molecular mechanisms that govern the autophagic response to nanoparticle internalization remain unclear.

Autophagic clearance is mediated by compartmentalization of cytoplasmic material into double-membrane vesicles called autophagosomes [34]. Fusion of autophagosomes with lysosomes results in the formation 
of autophagolysosomes where degradation occurs. As a result, autophagic clearance depends upon the coordinated regulation of autophagosome and lysosome biogenesis and function. The transcription factor EB (TFEB) is a master regulator of the lysosome-autophagy system, controlling expression of the CLEAR (coordinated lysosomal expression and regulation) gene network [35]. Activation of TFEB increases the numbers of lysosomes [35] and autophagosomes, which are needed for degradation of autophagic cargo [36]. Activation of TFEB has been observed upon internalization of synthetic nanoparticles [37] and autophagic clearance induced by ceria nanoparticles was found to specifically depend on TFEB activation [38].

Transcriptional activation of autophagy, however, is not always followed by an increase in autophagic clearance [39-43]. Nanoparticle uptake may result in impairment of downstream steps of the autophagy pathway, such as lysosomal function [27]. We hypothesize that nanoparticle-induced impairment of lysosomal function may affect lysosome-autophagosome fusion, possibly leading to blockage of autophagic flux and cytotoxicity.

A number of endocytosed nanoparticles are found to accumulate in lysosomes [44-47]. Cationic nanoparticles have been reported to induce autophagy, but also to disrupt lysosomes [12, 48, 49]. A "proton sponge" effect has been proposed as a potential mechanism for the observed lysosomal disruption and membrane permeabilization. Specifically, it was suggested that the high proton buffering capacity of the amino groups on the nanoparticle surface interferes with acidification of lysosomes, impairs the proton pump activity, and ultimately induces lysosomal membrane permeabilization [12].

We hypothesized that the surface charge of nanoparticles plays an important role in determining the nature of the autophagic response that is induced upon nanoparticle uptake. This hypothesis was investigated by testing the autophagic response activated upon cell exposure to non-functionalized polystyrene nanoparticles presenting neutral surfaces (PS), carboxyl-functionalized nanoparticles presenting anionic surfaces (PS-COOH), and amino-functionalized nanoparticles presenting cationic surfaces (PS- $\mathrm{NH}_{2}$ ). This study elucidates the cellular and molecular mechanisms that determine whether nanoparticle-mediated autophagy activation results in effective autophagic clearance or blockage of autophagic flux, thereby mapping the nanoparticle surface charge to biocompatible and bioadverse outcomes of nanoparticleinduce autophagy activation.

\section{Results}

\section{Characterization of polystyrene nanoparticles}

Zeta potential measurements were conducted to verify the surface charge of polystyrene nanoparticles $(50 \mathrm{~nm})$ functionalized with neutral (PS), anionic (PS-COOH) and cationic (PS- $\mathrm{NH}_{2}$ ) groups in water, PBS, and cell culture medium (Table 1). All the polystyrene NPs present negatively charged zeta potentials in cell culture medium due to the formation of a negatively charged protein corona, as previously reported [12].

Nanoparticle concentrations are reported in units of $\mu \mathrm{g} / \mathrm{mL}$ and were calculated assuming the density of the polystyrene nanoparticles in cell culture medium to approximately $1 \mathrm{~g} / \mathrm{cm}^{3}$.

\section{Polystyrene nanoparticles activate TFEB in HeLa/TFEB cells}

To investigate the molecular mechanisms involved in the autophagic response to nanoparticles of different surface charge, we first analyzed the transcriptional regulatory network that controls autophagy activation by monitoring TFEB intracellular localization in cells treated with PS, PS-COOH, and PS- $\mathrm{NH}_{2}$. TFEB localizes predominantly in the cytoplasm of resting cells and translocates into the nucleus upon activation [35]. We used HeLa cells stably transfected for the expression of TFEB-3xFLAG (HeLa/TFEB cells) because they provide an in vitro model system of TFEB activation [35]. HeLa/TFEB cells were treated with nanoparticles at final medium concentrations ranging from 10 to $100 \mu \mathrm{g} / \mathrm{mL}$ and TFEB intracellular localization was evaluated by confocal microscopy using Hoechst nuclear stain and an anti-FLAG antibody (Fig. 1a, b).

Table 1 Zeta potential and hydrodynamic diameter measurements of polystyrene nanoparticles in DI water, PBS, and cell culture medium

\begin{tabular}{|c|c|c|c|c|c|c|}
\hline & \multicolumn{3}{|c|}{ Zeta potential (mV) } & \multicolumn{3}{|c|}{ Hydrodynamic diameter (nm) } \\
\hline & DI water & PBS & Cell culture medium & DI water & PBS & Cell culture medium \\
\hline PS & $-8.0 \pm 2.0$ & $-16.7 \pm 11.0$ & $-13.9 \pm 0.6$ & $50.1 \pm 1.0$ & $49.4 \pm 3.6$ & $88.9 \pm 1.8$ \\
\hline PS- $\mathrm{COOH}$ & $-21.3 \pm 2.2$ & $-17.1 \pm 7.7$ & $-8.2 \pm 2.6$ & $60.3 \pm 5.0$ & $53.3 \pm 14.5$ & $53.5 \pm 14.3$ \\
\hline PS-NH ${ }_{2}$ & $+20.4 \pm 1.3$ & $+13.7 \pm 3.3$ & $-13.9 \pm 0.3$ & $74.8 \pm 16.2$ & $54.0 \pm 12.4^{\mathrm{a}}$ & $369.1 \pm 29.3$ \\
\hline
\end{tabular}

a A bimodal distribution of PS-NH2 in PBS indicates primary particles $(54.0 \pm 12.4 \mathrm{~nm})$ and aggregates with an average hydrodynamic diameter of $340.1 \pm 171.3 \mathrm{~nm}$ 


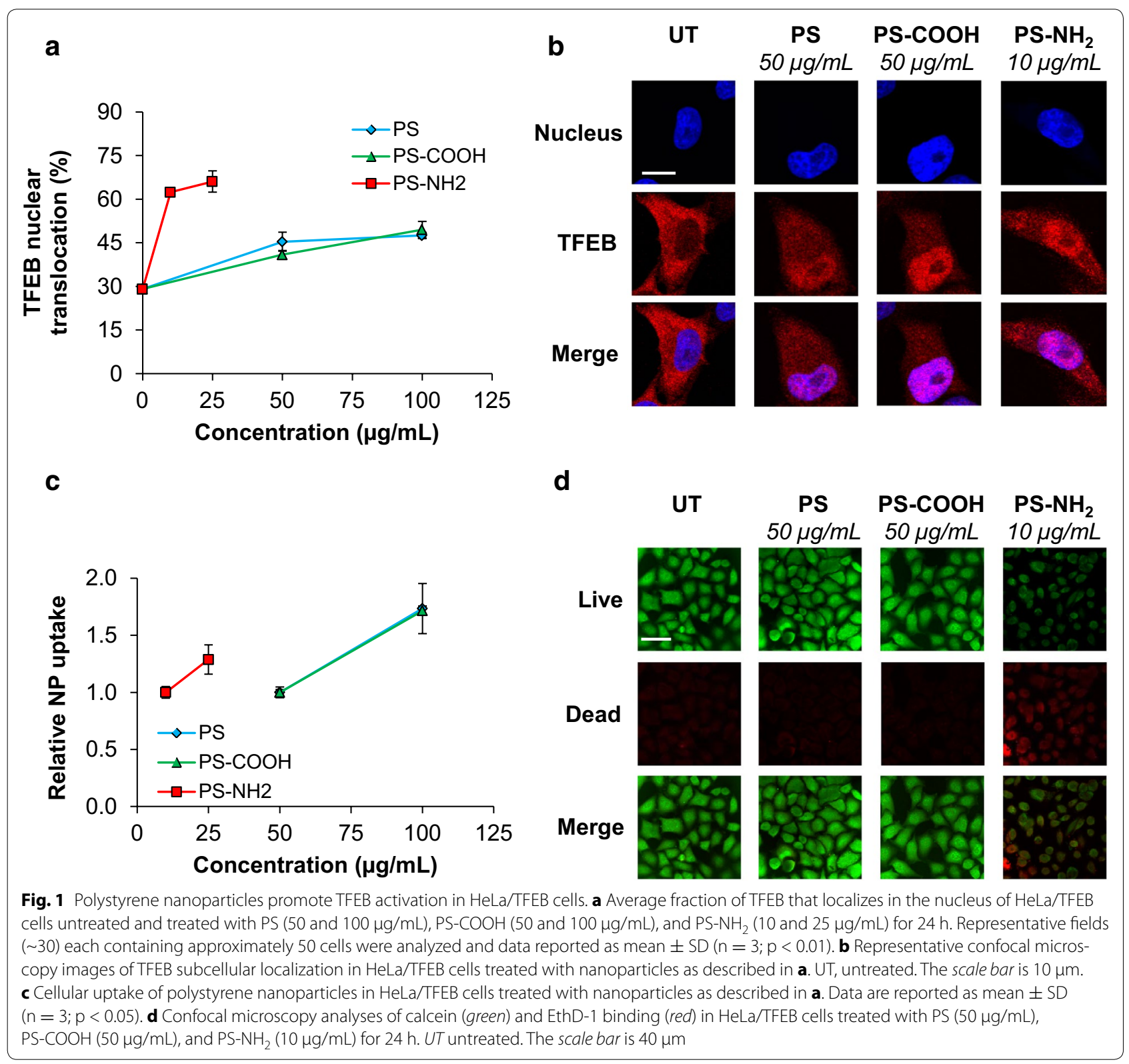

TFEB was found to localize predominantly in the cytoplasm of untreated HeLa/TFEB cells, as expected [35]. Specifically, the average fraction of TFEB that localizes in the nucleus of untreated cells was $29.1 \pm 1.7 \%$ (Fig. 1a). A significant increase in the fraction of TFEB that localizes in the nucleus was observed upon treatment with PS or PS$\mathrm{COOH}$ at medium concentrations of $50 \mu \mathrm{g} / \mathrm{mL}$ and higher. Specifically, the average fraction of TFEB that localizes in the nucleus was found to increase to over $40 \%$ after $24 \mathrm{~h}$ of cell treatment with PS ( $50 \mu \mathrm{g} / \mathrm{mL}: 45.4 \pm 3.3 \% ; 100 \mu \mathrm{g} / \mathrm{mL}$ : $47.5 \pm 1.0 \%$, Fig. $1 \mathrm{a} ; \mathrm{p}<0.01)$ or PS-COOH $(50 \mu \mathrm{g} / \mathrm{mL}$ : $40.9 \pm 1.4 \% ; 100 \mu \mathrm{g} / \mathrm{mL}: 49.5 \pm 2.8 \%$, Fig. $1 \mathrm{a} ; \mathrm{p}<0.01)$. Interestingly, the extent of TFEB activation was found not to reach a plateau upon cell treatment with concentrations of PS and PS-COOH higher than $100 \mu \mathrm{g} / \mathrm{mL}$. A dramatic increase in TFEB nuclear localization was observed in cells treated with lower concentrations of PS- $\mathrm{NH}_{2}$ (10 and $25 \mu \mathrm{g} / \mathrm{mL}$ ) compared to PS and PS-COOH. After $24 \mathrm{~h}$ of treatment with PS- $\mathrm{NH}_{2}$, the average fraction of TFEB that localizes in the nucleus was found to increase to over $60 \%$ $(10 \mu \mathrm{g} / \mathrm{mL}: 62.4 \pm 1.0 \% ; 25 \mu \mathrm{g} / \mathrm{mL}: 66.0 \pm 3.7 \%$, Fig. $1 \mathrm{a}$; $\mathrm{p}<0.01)$. Cell treatment with higher medium concentrations of PS- $\mathrm{NH}_{2}(50-100 \mu \mathrm{g} / \mathrm{mL})$ resulted in considerable cytotoxicity and cell death, precluding accurate evaluation of TFEB nuclear localization. Representative images are reported in Fig. 1b. 
These results indicate that cationic polystyrene nanoparticles induce TFEB activation in HeLa/TFEB cells to a higher extent than neutral and anionic nanoparticles and that the minimum concentration of cationic polystyrene nanoparticles needed to induce activation of TFEB is lower than that of neutral and anionic nanoparticles.

To investigate the correlation between activation of TFEB and uptake of polystyrene nanoparticles of different surface charge, we measured the extent of nanoparticle internalization in HeLa/TFEB cells under conditions observed to activate TFEB. Cellular uptake of fluorescently labeled polystyrene nanoparticles (PS, PS-COOH, and PS- $\mathrm{NH}_{2}$ ) was observed to follow a concentrationdependent behavior under the conditions used in this study (Fig. 1c). Interestingly, the extent of TFEB activation was not found to vary dramatically above a minimum concentration that depends on the nanoparticle surface charge. These results suggest that TFEB activation may function as a switch-like response that is activated upon uptake of a critical nanoparticle concentration.

Polystyrene nanoparticle-induced toxicity was analyzed under conditions that result in TFEB activation in HeLa/ TFEB cells. As expected, we found that cell treatment with PS or PS-COOH $(50 \mu \mathrm{g} / \mathrm{mL} ; 24 \mathrm{~h})$ does not cause cytotoxicity in HeLa/TFEB cells (Fig. 1d). Cell treatment with PS- $\mathrm{NH}_{2}(10 \mu \mathrm{g} / \mathrm{mL} ; 24 \mathrm{~h})$, however, results in considerable cytotoxicity (Fig. 1d), possibly due to elevation of lysosomal $\mathrm{pH}$ and impairment of lysosomal integrity $[10,12,48]$. These results suggest that the dramatic increase in TFEB activation observed in cells treated with low concentrations of PS- $\mathrm{NH}_{2}$ compared to PS or PS$\mathrm{COOH}$ may be due to lysosomal stress [50] caused by nanoparticle treatment under these conditions.

In summary, these studies indicate that cell treatment with neutral and anionic polystyrene nanoparticles $(50 \mu \mathrm{g} /$ $\mathrm{mL}$ ) does not induce cytotoxicity and results in activation of TFEB in HeLa/TFEB cells. However, treatment of the same cell line with cationic polystyrene nanoparticles at significantly lower concentrations $(10-25 \mu \mathrm{g} / \mathrm{mL})$ induces a higher extent of TFEB activation and cytotoxicity compared to neutral and anionic nanoparticles. Higher concentrations of cationic nanoparticles $(>25 \mu \mathrm{g} / \mathrm{mL})$ were found to cause excessive cytotoxicity and cell death.

\section{Polystyrene nanoparticles activate TFEB in PC12 cells}

To further investigate how polystyrene nanoparticle surface charge affects TFEB activation under conditions that do not induce significant cellular stress, we tested the impact of polystyrene nanoparticles with neutral, anionic, and cationic surface charge on TFEB intracellular localization in PC12 cells. PC12 cells were selected for these studies because they are more resistant to many of the cytotoxic effects induced by the uptake of cationic nanoparticles including lysosomal permeabilization, mitochondrial damage, and increased intracellular and mitochondrial calcium levels [12]. PC12 cells were treated with nanoparticles $(10-100 \mu \mathrm{g} / \mathrm{mL}$; $24 \mathrm{~h}$ ) and TFEB intracellular localization was evaluated and quantified as described above (Fig. 2a). TFEB localizes predominantly in the cytoplasm of untreated $\mathrm{PC} 12$ cells, as observed in HeLa/TFEB cells. Specifically, the average fraction of TFEB that localizes in the nucleus of untreated cells was found to be $30.7 \pm 0.7 \%$ of the total TFEB (Fig. 2a). TFEB nuclear translocation was found to increase to over $50 \%$ upon cell treatment with PS- $\mathrm{NH}_{2}$ $(50 \mu \mathrm{g} / \mathrm{mL}: 51.8 \pm 5.3 \% ; 100 \mu \mathrm{g} / \mathrm{mL}: 51.7 \pm 7.1 \%)$, but not in cells treated with PS or PS-COOH at the same concentration (Fig. 2a; p < 0.01). Representative images are reported in Fig. 1b.

Similar to what was observed in experiments conducted using HeLa/TFEB cells (Fig. 1c), analyses of nanoparticle uptake revealed an increase in nanoparticle uptake as a function of nanoparticle concentration in PC12 cells treated with PS and PS-COOH (Fig. 2c). However, the internalization of $\mathrm{PS}-\mathrm{NH}_{2}$ was found not to increase with nanoparticle concentration, suggesting again that TFEB activation may function as a switch-like response that is activated upon uptake of a critical nanoparticle concentration.

Cytotoxicity analyses in PC12 treated with polystyrene nanoparticles revealed that, similar to HeLa/TFEB cells (Fig. 1), neither PS nor PS-COOH alter cell viability, while treatment with PS- $\mathrm{NH}_{2}$ results in considerable toxicity at the concentrations tested (Fig. 2d).

Collectively, these results indicate that cell exposure to polystyrene nanoparticles of different surface charge (neutral, anionic, cationic) results in activation of TFEB. These results also show that cationic polystyrene nanoparticles induce TFEB activation to a higher level than neutral or anionic polystyrene nanoparticles in all cell lines tested, both in terms of the extent of TFEB nuclear translocation and in terms of the minimal concentration of nanoparticle needed to observe TFEB activation. Moreover, the minimum medium concentration of cationic nanoparticles that result in activation of TFEB in PC12 cells, which are more resistant to cationic nanoparticle-induced cytotoxicity [12], was found to be higher than that observed in HeLa/TFEB cells, suggesting a correlation between sensitivity to cationic nanoparticles and TFEB activation.

\section{Clearance of autophagic cargo upon internalization of polystyrene nanoparticles depends on nanoparticle surface charge}

To test whether polystyrene nanoparticle-induced TFEB activation parallels autophagic clearance, we monitored 


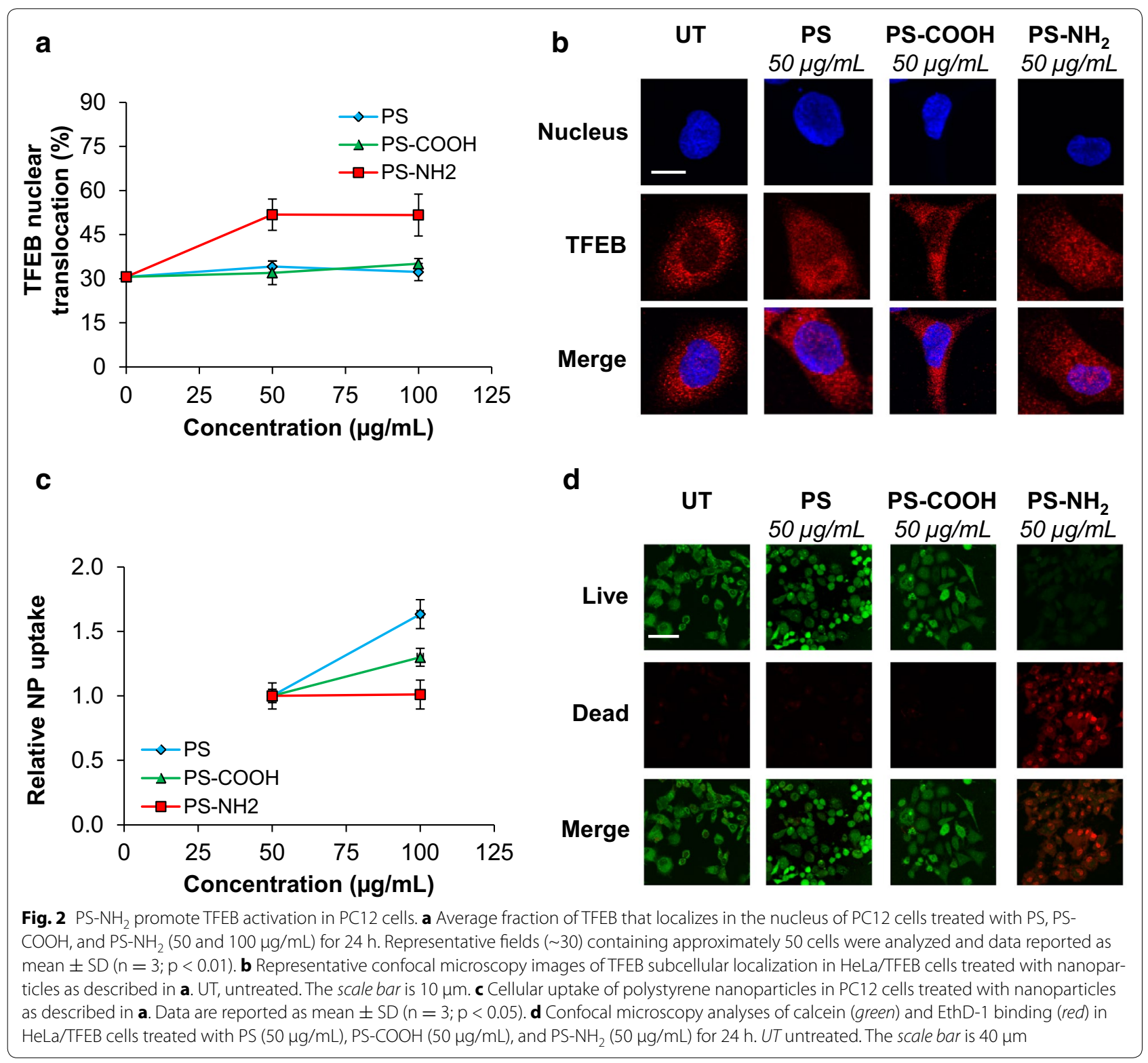

the degradation of autophagic cargo. We used fibroblasts derived from a patient with late infantile neuronal ceroid lipofuscinosis (LINCL) which are characterized by accumulation of ceroid lipopigment [51]. Ceroid lipopigment is a lipofuscin-like autofluorescent material [52] normally degraded through autophagy; LINCL cells thus provide a reliable in vitro model system to quantify autophagic clearance. Preliminary studies were conducted to evaluate the minimum medium concentration of polystyrene nanoparticles required to activate TFEB in LINCL fibroblasts, as results obtained with HeLa/ TFEB and PC12 cells suggest that the extent of TFEB activation is cell type dependent. Cells were exposed to nanoparticles for 3 days, an incubation time necessary to monitor autophagic clearance [38]. Cell treatment with polystyrene nanoparticles (neutral, anionic and cationic) at $25 \mu \mathrm{g} / \mathrm{mL}$ causes an increase in the fraction of TFEB that localizes into the nucleus, compared to untreated cells (Fig. 3a, red). TFEB activation was observed upon treatment with low concentrations $(25 \mu \mathrm{g} / \mathrm{mL})$ of all three types of polystyrene nanoparticles possibly due to the prolonged time of incubation (3 days) of LINCL fibroblasts compared to HeLa/TFEB cells and PC12 cells (24 h).

Accumulation of ceroid lipopigment was monitored in LINCL fibroblasts treated with polystyrene 

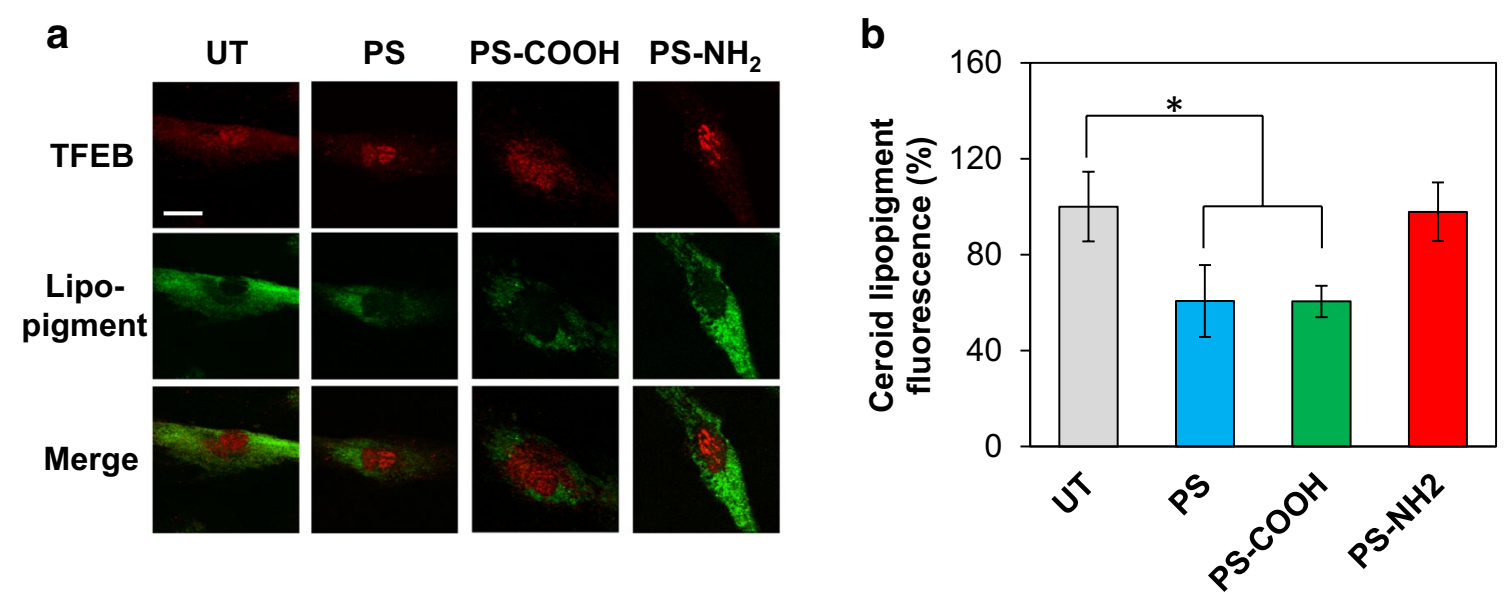

Fig. 3 Accumulation of ceroid lipopigment in LINCL fibroblasts treated with polystyrene nanoparticles. a Confocal microscopy analyses of TFEB (red) and ceroid lipopigment (green) in LINCL fibroblasts treated with PS, PS-COOH or PS-NH 2 (25 $\mu \mathrm{g} / \mathrm{mL})$ for 3 days and evaluated by detecting green autofluorescence and binding of anti-TFEB antibody, respectively. UT untreated. The scale bar is $20 \mu \mathrm{m}$. b Quantification of ceroid lipopigment fluorescence intensity calculated as described in the "Methods". Data are reported as mean \pm SD $\left(n=15 ;{ }^{*} p<0.01\right)$

nanoparticles under conditions found to activate TFEB. Confocal microscopy analyses showed that accumulation of ceroid lipopigment was reduced in cells treated with PS or PS-COOH (Fig. 3a, green). Specifically, the fluorescence intensity of ceroid lipopigment decreased to approximately $60 \%$ of the fluorescence intensity of untreated cells after treatment with PS or PS-COOH (PS: $60.7 \pm 15.0 \%$; PS-COOH: $60.5 \pm 6.5 \%$, Fig. $3 b ; p<0.01)$. Treatment with PS- $\mathrm{NH}_{2}$ under the same condition, however, was found not to affect the accumulation of ceroid lipopigment (Fig. 3a, green) despite the remarkable effect of PS- $\mathrm{NH}_{2}$ on TFEB activation. PS- $\mathrm{NH}_{2}$ treatment at higher concentrations resulted in considerable induction of cytotoxicity precluding accurate evaluation of ceroid lipopigment accumulation.

\section{Cationic polystyrene nanoparticles impair lysosomal integrity and block autophagic flux}

Autophagic clearance relies on the coordinated activation of lysosome and autophagosome biogenesis and function [53]. In addition to being transcriptionally upregulated, both branches of the lysosome-autophagy system need to be functionally active to promote autophagic clearance [39-43]. If lysosomal activity is impaired, transcriptional upregulation of autophagy genes and increased formation of autophagosomes are ultimately associated with decreased autophagic clearance [27].

To investigate the impact of the surface charge of polystyrene nanoparticles on lysosomal function, we assessed lysosomal integrity in fibroblasts treated with PS, PS$\mathrm{COOH}$, and $\mathrm{PS}-\mathrm{NH}_{2}$. Fibroblasts were treated with polystyrene nanoparticles $(25 \mu \mathrm{g} / \mathrm{mL})$ and collected every
$24 \mathrm{~h}$ for up to $72 \mathrm{~h}$. Lysosomal integrity was evaluated using acridine orange (AO), a lysosomotropic probe that accumulates in acidic organelles and exhibits red fluorescence. The red fluorescence of AO dissipates upon lysosomal membrane permeabilization when the dye is released into a more neutral environment. Therefore, a decrease in fluorescence intensity indicates abnormalities in lysosomal $\mathrm{pH}$, or disruption of the lysosomal membrane. The fluorescence intensity of AO in cells treated with polystyrene nanoparticles was measured using flow cytometry, and lysosomal impairment was evaluated by calculating the percentage of cells that present low AO fluorescence as described in the Methods ( $\mathrm{AO}^{\text {low }}$ cells; Fig. 4a). The total $\mathrm{AO}$ fluorescence relative to untreated cells was also quantified to evaluate lysosomal integrity in the entire cell population (Fig. 4b). Treatment with $\mathrm{PS}-\mathrm{NH}_{2}$ but not with PS or PS-COOH was found to increase the percentage of cells presenting low AO fluorescence (Fig. 4a), indicating an increase in the number of cells with lysosomal impairment upon PS- $\mathrm{NH}_{2}$ treatment. In addition, a significant decrease in the total AO fluorescence intensity in cells treated with PS- $\mathrm{NH}_{2}$ was observed, suggesting an average decrease in lysosomal integrity (Fig. 4b). Representative histograms of cells treated with different types of polystyrene nanoparticle after 24 and $72 \mathrm{~h}$ are reported in Fig. 4c. Collectively, these results suggest that cationic polystyrene nanoparticles impair lysosomal integrity.

Because impairment of lysosomal integrity observed in cells treated with cationic nanoparticles may result from an increase in lysosomal $\mathrm{pH}$ induced upon accumulation of cationic nanoparticles within lysosomes [10, 54], we asked whether the nanoparticles investigated 


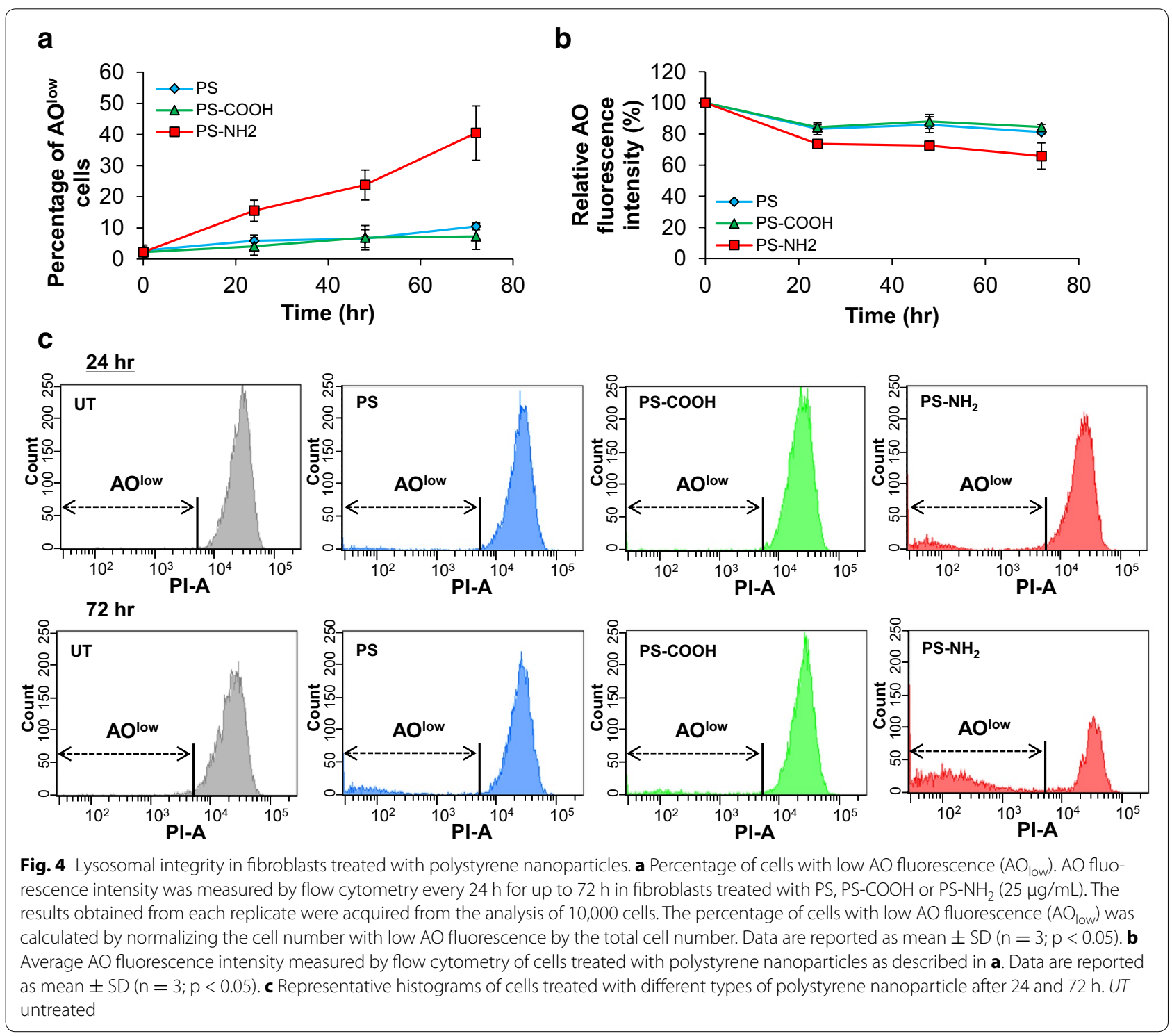

in this study accumulate in the lysosomes under conditions found to affect lysosomal integrity. Lysosomal accumulation of polystyrene nanoparticles was evaluated by testing the colocalization of polystyrene nanoparticles and LAMP-2, a protein that resides on the membrane of lysosomes, using confocal microscopy [55]. All three types of polystyrene nanoparticles (PS, PS-COOH, and PS- $\mathrm{NH}_{2}$ ) were found to accumulate in lysosomes at each time point investigated $(25 \mu \mathrm{g} / \mathrm{mL} ; 24,48$, and $72 \mathrm{~h}$ ) (see Additional file 1). Because lysosomal function and integrity depends on the acidic $\mathrm{pH}$ of the lysosomal environment [56-58], these results suggest that impairment of lysosomal integrity observed upon uptake of cationic nanoparticles is possibly an effect of the nanoparticle surface charge. These results would also explain why neutral and anionic nanoparticles were found to accumulate in the lysosome at each time point investigated, but were found not to affect lysosomal integrity.

Lysosomal membrane permeabilization may compromise lysosome-autophagosome fusion. To test whether polystyrene nanoparticle treatment impairs lysosomeautophagosome fusion, autophagolysosome formation was monitored under conditions that caused a change in lysosomal integrity. We evaluated the colocalization of LC3 and LAMP-2, which are proteins on the membranes of autophagosomes [59], and lysosomes [55], respectively. Fibroblasts were treated with nanoparticles $(25 \mu \mathrm{g} /$ $\mathrm{mL}$ ) for up to $72 \mathrm{~h}$. Colocalization was evaluated using confocal microscopy and quantified as described in the "Methods" (Fig. 5a). A significant increase in the extent 


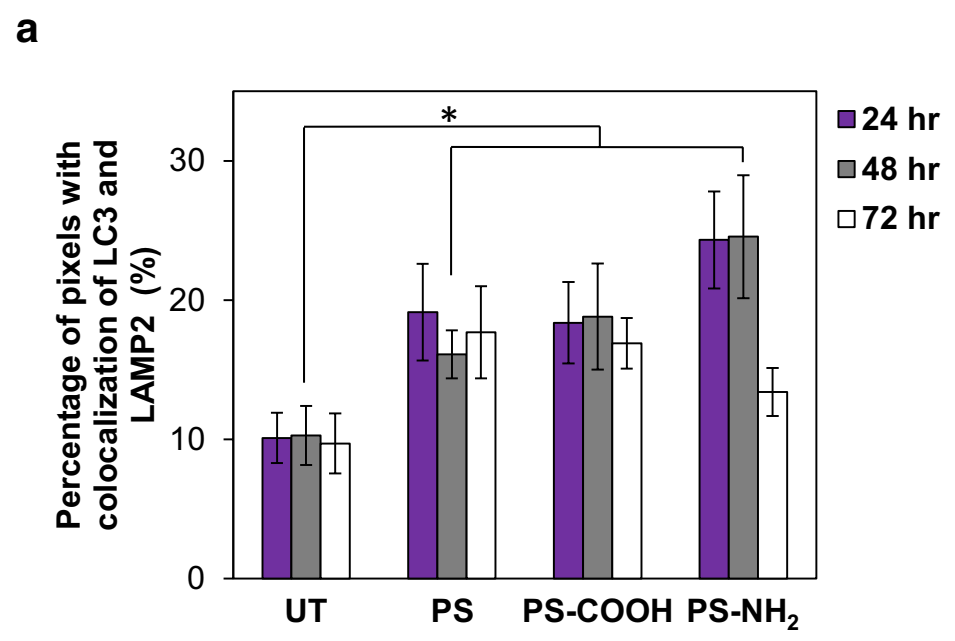

b

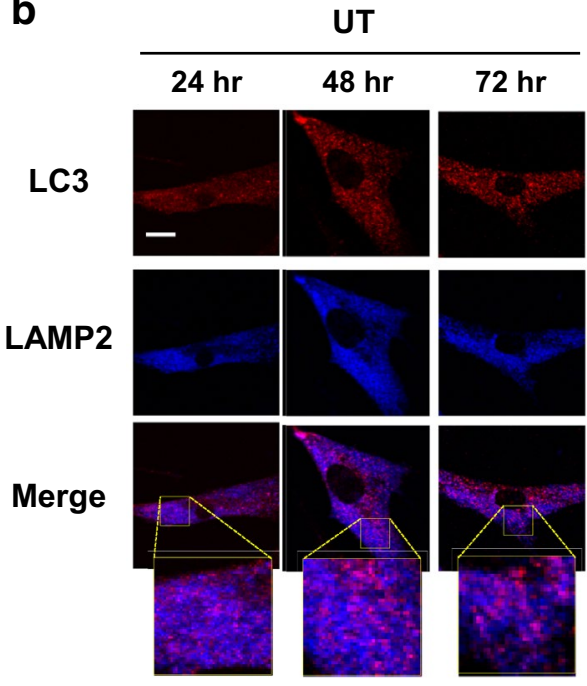

C

d

e
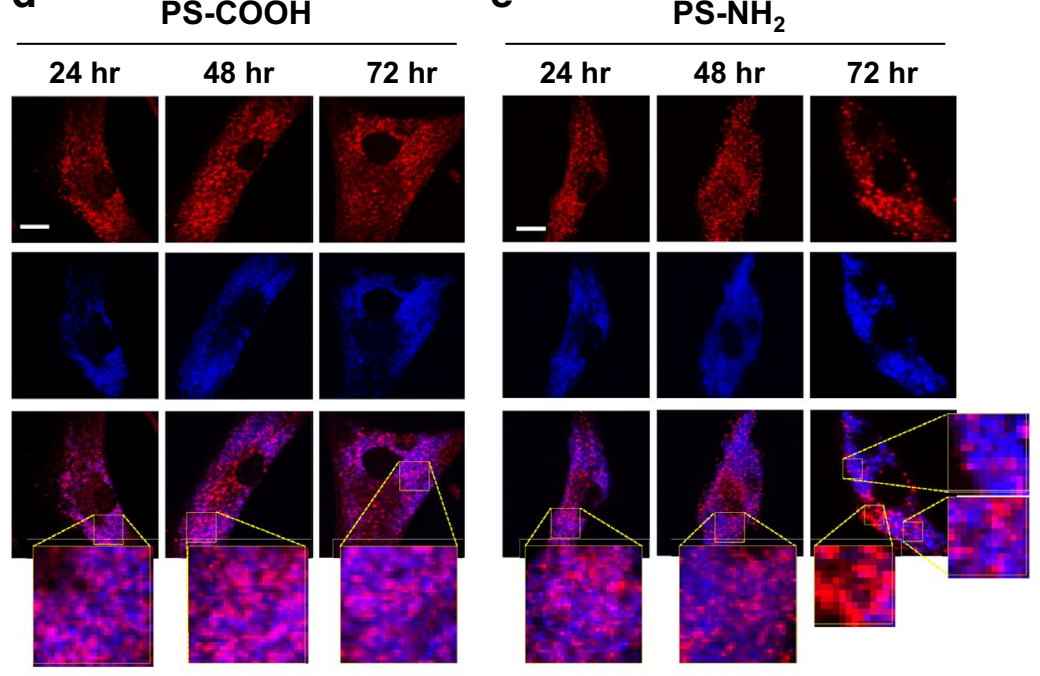

Fig. 5 Colocalization of LC3 and LAMP-2 in fibroblasts treated with polystyrene nanoparticles. a Quantification of LC3-LAMP-2 colocalization in fibroblasts treated with polystyrene nanoparticles $(50 \mathrm{~nm} ; 25 \mu \mathrm{g} / \mathrm{mL}$ ) calculated as described in the "Methods". UT untreated. Data are reported as mean $\pm S D\left(n=15 ;{ }^{*} p<0.01\right)$. b-e Representative confocal microscopy images of LC3 (red) and LAMP-2 (blue) in b untreated fibroblasts (UT) and in fibroblasts treated with c PS $(25 \mu \mathrm{g} / \mathrm{mL})$, d PS-COOH $(25 \mu \mathrm{g} / \mathrm{mL})$, e PS- $\mathrm{NH}_{2}(25 \mu \mathrm{g} / \mathrm{mL})$ after 24,48 , and $72 \mathrm{~h}$ evaluated by detecting binding of anti-LC3 antibody and binding of anti-LAMP-2 antibody, respectively. Colocalization of LC3 (red) and LAMP-2 (blue) is shown in merged images (purple). The scale bar is $20 \mu \mathrm{m}$

of LC3 and LAMP-2 colocalization was observed in cells treated with PS or PS-COOH compared to untreated cells (untreated: $10.1 \pm 1.8 \%$ after $24 \mathrm{~h}, 10.3 \pm 2.1 \%$ after 48 h, $9.7 \pm 2.2 \%$ after 72 h. PS: $19.1 \pm 3.4 \%$ after $24 \mathrm{~h}, 16.1 \pm 1.7 \%$ after $48 \mathrm{~h}, 17.7 \pm 3.3 \%$ after $72 \mathrm{~h}$. PS-COOH: $18.4 \pm 2.9 \%$ after 24 h, $18.8 \pm 3.8 \%$ after 48 h, $16.9 \pm 1.8 \%$ after 72 h) (Fig. $5 \mathrm{a} ; p<0.01$ ), indicating that neutral and anionic polystyrene nanoparticles promote fusion of autophagosomes and lysosomes and formation of autophagolysosomes. The extent of colocalization of LC3 and LAMP-2 in cells treated with PS- $\mathrm{NH}_{2}$ reached $24.3 \pm 3.5 \%$ after $24 \mathrm{~h}$ of incubation and $24.6 \pm 4.4 \%$ after $48 \mathrm{~h}$, but decreased to $13.7 \pm 1.7 \%$ after $72 \mathrm{~h}$ (Fig. 5a; $p<0.01$ ), indicating that formation of autophagolysosomes is ultimately impaired by cationic nanoparticle treatment. Representative images of untreated cells and cells treated with PS, PS-COOH and PS- $\mathrm{NH}_{2}$ are reported in Fig. 5b-e.

These results indicate that lysosomal accumulation of nanoparticles presenting neutral and negative surface 
charges cause induction of the autophagic response through activation of TFEB, which manifests as an increase in lysosome-autophagosome fusion and, ultimately, enhanced clearance of autophagic cargo. Lysosomal accumulation of nanoparticles presenting positive surface charge, however, causes activation of the autophagic response, but also lysosomal dysfunction. As a result, internalization of polystyrene nanoparticles presenting positive surface charge eventually manifests as blockage of autophagic flux and does not result in a change in clearance of autophagic cargo.

\section{Discussion}

In this study, we investigated the molecular mechanisms associated with the autophagic response to polystyrene nanoparticles as a function of nanoparticle surface charge. Cationic nanoparticles were found to induce activation of TFEB, a master regulator of lysosome biogenesis and autophagy, to a higher level than neutral or anionic nanoparticles, both in terms of the extent of TFEB nuclear localization and the minimal concentration of nanoparticle needed to observe an increase in TFEB activation.

Downstream steps of the autophagy pathway, namely lysosomal function, lysosome-autophagosome fusion, and clearance of autophagic cargo were also monitored to establish a correlation between transcriptional activation of autophagy and the nature of the autophagic response induced upon uptake of nanoparticles. Cell treatment with neutral and anionic polystyrene nanoparticles was found to upregulate the autophagy system, enhance autophagic activity, and, ultimately, increase clearance of autophagic substrates. Cell treatment with cationic polystyrene nanoparticles, on the other hand, was found to cause impairment of lysosomal integrity, reduced formation of autophagolysosomes and, ultimately, blockage of autophagic flux. As a result, activation of the autophagic response observed in cells treated with cationic nanoparticles does not parallel an increase in degradation of autophagic substrates.

Nanoparticle aggregation is commonly observed upon cellular internalization, typically due to the high ionic strength conditions of the cytosolic environment $[8,60]$; whether nanoparticle aggregation plays a role in the activation of TFEB observed in response to cell treatment with polystyrene nanoparticles remains to be determined.

High levels of both autophagy and cell death are often observed under stress conditions induced by accumulation of positively charged nanoparticles in lysosomes, suggesting that cell death under these conditions is mediated by autophagy. Generally speaking, a number of stressful stimuli that ultimately lead to cell death initially induce activation of autophagy as a pro-survival pathway. This observation has led to the assumption that autophagy contributes to cell death [30]. Cell death by autophagy, however, is expected to result in upregulation of the autophagy system including increase in autophagic flux [61, 62]. Interestingly, cationic nanoparticles induce activation of TFEB that is not paralleled by increase in degradation of autophagic cargo but rather by impairment of lysosomal function, suggesting that cell death under these conditions is not caused by autophagy, but rather by impairment of autophagy.

This study provides a mechanistic understanding of the interaction of polystyrene nanoparticles of different surface charges with the autophagic pathway and contributes to defining the design rules for engineering nanoparticles with desired effect on the autophagy system and nanotherapeutics for the treatment of diseases characterized by inefficient autophagic activity and accumulation of storage material.

\section{Conclusions}

These results demonstrate that cell exposure to neutral and anionic polystyrene nanoparticles results in TFEB activation, enhancement of autophagic activity, and, ultimately, increased degradation of autophagic cargo. Cationic polystyrene nanoparticles induce activation of TFEB, but also cause impairment of lysosomal integrity, reduced formation of autophagolysosomes, and, ultimately, blockage of autophagic flux.

\section{Methods}

\section{Reagents and cell cultures}

Polystyrene nanoparticles were purchased from Magsphere or Phosphorex (see Additional file 2). Bafilomycin was purchased from Cayman Chemical, Acridine Orange was from Invitrogen. Cell culture medium, PBS, and TrypLE Express were from Lonza.

Fibroblasts derived from Late Infantile Neuronal Ceroid Lipofuscinosis (LINCL) patients were from Coriell Cell Repositories (GM16486). HeLa cells stably transfected for the expression of TFEB-3xFLAG were a gift from Dr. Sardiello [35]. Cells were grown at $37^{\circ} \mathrm{C}$ in $5 \% \mathrm{CO}_{2}$ in Dulbecco's Modified Eagle Medium supplemented with heat-inactivated fetal bovine serum $(20 \%$ FBS for LINCL fibroblasts, $10 \%$ FBS for HeLa cells) and $1 \%$ glutamine Pen-Strep. Monolayers were passaged with TrypLE Express.

PC12 cells were from ATCC. Cells were grown at $37{ }^{\circ} \mathrm{C}$ in $5 \% \mathrm{CO}_{2}$ in Dulbecco's Modified Eagle Medium supplemented with $5 \%$ heat-inactivated fetal bovine serum, $10 \%$ horse serum and $1 \%$ glutamine Pen-Strep. Monolayers were passaged with TrypLE Express. 


\section{Characterization of nanoparticles}

The surface charge and hydrodynamic diameter of polystyrene nanoparticles was analyzed using a Brookhaven Instruments ZetaPALS system and a Beckman Coulter DelsaMax Pro system.

\section{Cellular uptake of polystyrene nanoparticles}

Nanoparticle uptake was evaluated as previously reported [63]. Briefly, $10^{4}$ cells were plated in each well of 96-well plates and incubated overnight. Cells were exposed to nanoparticles for $24 \mathrm{~h}$, washed three times with PBS, and lysed with the complete lysis-M buffer containing the protease inhibitor cocktail (Roche). The fluorescence intensity of the cell lysate was quantified using a SpectraMax Gemini plate reader (Molecular Device) (excitation $488 \mathrm{~nm}$, emission $530 \mathrm{~nm}$ ). The fluorescence intensity of cell lysates was normalized to the absolute fluorescence of each corresponding nanoparticle to calculate the intracellular concentration of polystyrene nanoparticles.

\section{Immunofluorescence assays}

TFEB intracellular localization was evaluated by confocal microscopy using Hoechst nuclear stain (Enzo Life Sciences), and an anti-FLAG antibody (Sigma-Aldrich) or an anti-TFEB antibody (Abcam Inc). The percentage of TFEB nuclear localization was calculated by normalizing the fluorescence intensity of TFEB that localizes in the nucleus by the total fluorescence intensity of TFEB in each cell measured using MATLAB. Average values were calculated over 30 images each containing $\sim 50$ cells and collected from at least three independent experiments.

The accumulation of ceroid lipopigment was quantified as previously described [52]. Average values were calculated over 30 images each containing $\sim 5-10$ cells and collected from at least three independent experiments.

The colocalization of LC3 (red) and LAMP-2 (blue) was evaluated by confocal microscopy using an anti-LC3 antibody (Novus Biologics) and an anti-LAMP-2 antibody (BioLegend). Colocalization was quantified by calculating the number of pixels with both red and blue signals above a predefined brightness threshold (grey scale $>30$, range $0-255$ ) and with a red to blue ratio within a predefined range (0.5-2). The percentage of colocalization was calculated by normalizing the number of pixels presenting LC3 and LAMP-2 colocalization to the total number of pixels in each cell over the entire image. Average values were calculated over 30 images each containing $\sim 5-10$ cells and collected from at least three independent experiments.

\section{Cell viability assays}

Cell viability assays were performed using the LIVE/ DEAD $^{\circledR}$ Viability/Cytotoxicity assay according to the manufacturer's specifications (Life Technologies). Images were obtained using an Olympus IX81 confocal microscope and co-localized using Fluoview software.

\section{Lysosomal integrity assays}

Lysosomal integrity was analyzed using acridine orange (AO) as previously described [12]. Cells were incubated with nanoparticles for $24 \mathrm{~h}$ and exposed to $1 \mu \mathrm{g} / \mathrm{mL} \mathrm{AO}$ for $15 \mathrm{~min}$ at $37{ }^{\circ} \mathrm{C}$. Samples $(10,000$ cells) were analyzed by flow cytometry (FACSCanto ${ }^{\text {TM }}$ II) using a 488$\mathrm{nm}$ Argon laser and a 670-nm emission filter. The cell population presenting low AO fluorescence was defined by setting the gate boundary corresponding to $2 \%$ of untreated cells presenting low AO fluorescence.

\section{Statistical analyses}

All data is presented as mean \pm S.D., and statistical significance was calculated using a two-tailed $t$ test.

\section{Additional files}

Additional file 1. Lysosomal accumulation of polystyrene nanoparticles. Confocal microscopy analyses of polystyrene nanoparticles (green) and LAMP-2 (blue) in fibroblasts treated with polystyrene nanoparticles $(50 \mathrm{~nm} ; 25 \mu \mathrm{g} / \mathrm{mL}$ ), evaluated every $24 \mathrm{~h}$ for up to $72 \mathrm{~h}$ by detecting the fluorescence intensity of fluorescently labeled polystyrene nanoparticles and binding of anti-LAMP-2 antibody, respectively. Colocalization of polystyrene nanoparticles (green) and LAMP-2 (blue) is shown in merged images. UT, untreated. The scale bar is $20 \mu \mathrm{m}$.

Additional file 2. Polystyrene nanoparticle purchasing information.

\section{Abbreviations}

AO: Acridine orange; CLEAR: Coordinated lysosomal expression and regulation; LAMP: Lysosome-associated membrane protein; LC3: Light-chain 3; LINCL: Late infantile neuronal ceroid lipofuscinosis; PS: Polystyrene nanoparticles; PS- $\mathrm{NH}_{2}$ : Amine-functionalized polystyrene nanoparticles; PS-COOH: Carboxyl-functionalized polystyrene nanoparticles; TFEB: Transcription Factor EB.

\section{Authors' contributions}

LS conceived of the study and participated in its design and coordination. WS supervised the study and contributed to the selection of methodologies and analysis of the obtained results. WS, LP, JY, and AK conducted the experiments. WS, LP, and LS drafted the manuscript. All authors read and approved the final manuscript.

\section{Author details}

${ }^{1}$ Department of Chemical and Biomolecular Engineering, Rice University, Houston, TX 77005, USA. ${ }^{2}$ Department of Biochemistry and Cell Biology, Rice University, Houston, TX 77005, USA. ${ }^{3}$ Department of Bioengineering, Rice University, Houston, TX 77005, USA.

\section{Acknowledgements}

This work was funded by The National Science Foundation (CBET-1336053 and CBET-1254318) and the Welch Foundation (C-1824). 


\section{Competing interests}

The authors report no conflicts of interest. The authors alone are responsible for the content and writing of the paper.

Received: 11 September 2015 Accepted: 13 November 2015 Published online: 23 November 2015

\section{References}

1. Wilczewska A, Niemirowicz K, Markiewicz K, Car H. Nanoparticles as drug delivery systems. Pharmacol Rep. 2012;64:1020-37.

2. De Jong WH, Borm PJ. Drug delivery and nanoparticles: applications and hazards. Int J Nanomed. 2008;3:133-49.

3. Argyo C, Weiss V, Bräuchle C, Bein T. Multifunctional mesoporous silica nanoparticles as a universal platform for drug delivery. Chem Mater. 2014;26:435-51.

4. Brigger I, Dubernet C, Couvreur P. Nanoparticles in cancer therapy and diagnosis. Adv Drug Deliv Rev. 2002;54:631-51.

5. Mieszawaska A, Mulder WJ, Fayad ZA, Cormode DP. Multifunctional gold nanoparticles for diagnosis and therapy of disease. Mol Pharm. 2013;10:831-47.

6. Ribeiro N, Sousa S, van Blitterswijk C, Moroni L, Monteiro F. A biocompos ite of collagen nanofibers and nanohydroxyapatite for bone regeneration. Biofabrication. 2014;6:035015.

7. Murugan R, Ramakrishna S. Bioresorbable composite bone paste using polysaccharide based nano hydroxyapatite. Biomaterials. 2004;25:3829-35

8. Albanese A, Chan WCW. Effect of gold nanoparticle aggregation on cell uptake and toxicity. ACS Nano. 2011;5:5478-89.

9. Hussain S, Al-Nsour F, Rice AB, Marshburn J, Yingling B, Ji Z, Zink Jl, Walker NJ, Garantziotis S. Cerium dioxide nanoparticles induce apoptosis and autophagy in human peripheral blood monocytes. ACS Nano. 2012;6:5820-9.

10. Lunov O, Syrovets T, Loos C, Nienhaus GU, Mailander V, Landfester K, Rouis M, Simmet T. Amino-functionalized polystyrene nanoparticles activate the NLRP3 inflammasome in human macrophages. ACS Nano. 2011;5:9648-57.

11. Xia T, Kovochich M, Liong M, Mädler L, Gilbert B, Shi H, Yeh Jl, Zink Jl, Nel AE. Comparison of the mechanism of toxicity of zinc oxide and cerium oxide nanoparticles based on dissolution and oxidative stress properties. ACS Nano. 2008;2:2121-34.

12. Xia T, Kovochich M, Liong M, Zink JI, Nel AE. Cationic polystyrene nanosphere toxicity depends on cell-specific endocytic and mitochondrial injury pathways. ACS Nano. 2008;2:85-96.

13. Halamoda Kenzaoui B, Chapuis Bernasconi C, Guney-Ayra S, JuilleratJeanneret L. Induction of oxidative stress, lysosome activation and autophagy by nanoparticles in human brain-derived endothelial cells. Biochem J. 2012:441:813-21.

14. Goodman C, McCusker C, YilmazT, Rotello V. Toxicity of gold nanoparticles functionalized with cationic and anionic side chains. Bioconjug Chem. 2004;15:897-900

15. Pelaz B, Charron G, Pfeiffer C, Zhao Y, de la Fuente J, Liang X, Parak W, Del Pino P. Interfacing engineered nanoparticles with biological systems: anticipating adverse nano-bio interactions. Small. 2013;9:1573-84.

16. Nel AE, Mädler L, Velegol D, Xia T, Hoek EMV, Somasundaran P, Klaessig F, Castranova V, Thompson M. Understanding biophysicochemical interactions at the nano-bio interface. Nat Mater. 2009;8:543-57.

17. Li H, LiY, Jiao J, Hu H-M. Alpha-alumina nanoparticles induce efficient autophagy-dependent cross-presentation and potent antitumour response. Nat Nanotechnol. 2011;6:645-50.

18. Li JJ, Hartono D, Ong C-N, Bay B-H, Yung L-YL. Autophagy and oxidative stress associated with gold nanoparticles. Biomaterials. 2010;31:5996-6003

19. Seleverstov O, Zabirnyk O, Zscharnack M, Bulavina L, Nowicki M, Heinrich J-M, Yezhelyev M, Emmrich F, O'Regan R, Bader A. Quantum dots for human mesenchymal stem cells labeling. A size-dependent autophagy activation. Nano Lett. 2006;6:2826-32.

20. Yu L, Lu Y, Yu S, Wen L. Rare earth oxide nanocrystals induce autophagy in HeLa cells. Small. 2009;5:2784-7.
21. Zhang Q, Yang W, Man N, Zheng F, Shen Y, Sun K, Li Y, Wen L. Autophagymediated chemosensitization in cancer cells by fullerene $C 60$ nanocrystal. Autophagy. 2009;5:1107-17.

22. Wang C-W, Klionsky DJ. The molecular mechanism of autophagy. Mol Med. 2003;9:65-76.

23. Khan Ml, Mohammad A, Patil G, Naqvi SAH, Chauhan LKS, Ahmad I. Induction of ROS, mitochondrial damage and autophagy in lung epithelial cancer cells by iron oxide nanoparticles. Biomaterials. 2012:33:1477-88.

24. Man N, Yu L, Wen L. Rare earth oxide nanocrystals as a new class of autophagy inducers. Autophagy. 2010;6:310-1.

25. Markovic ZM, Ristic BZ, Arsikin KM, Klisic DG, Harhaji-Trajkovic LM, Todorovic-Markovic BM, Kepic DP, Kravic-Stevovic TK, Jovanovic SP, Milenkovic MM, Milivojevic DD, Bumbasirevic VZ, Dramicanin MD, Trajkovic VS. Graphene quantum dots as autophagy-inducing photodynamic agents. Biomaterials. 2012;33:7084-92.

26. Lee C-M, Huang S-T, Huang S-H, Lin H-W, Tsai H-P, Wu J-Y, Lin C-M, Chen C-T. C60 fullerene-pentoxifylline dyad nanoparticles enhance autophagy to avoid cytotoxic effects caused by the $\beta$-amyloid peptide. Nanomedicine. 2011;7:107-14.

27. Ma X, Wu Y, Jin S, Tian Y, Zhang X, Zhao Y, Yu L, Liang X-J. Gold nanoparticles induce autophagosome accumulation through size-dependent nanoparticle uptake and lysosome impairment. ACS Nano. 2011;5:8629-39.

28. Lee $Y-H$, Cheng F-Y, Chiu H-W, Tsai J-C, Fang C-Y, Chen C-W, Wang Y-J. Cytotoxicity, oxidative stress, apoptosis and the autophagic effects of silver nanoparticles in mouse embryonic fibroblasts. Biomaterials. 2014;35:4706-15

29. Eidi H, Joubert O, Némos C, Grandemange S, Mograbi B, Foliguet B, Tournebize J, Maincent P, Le Faou A, Aboukhamis I, Rihn BH. Drug delivery by polymeric nanoparticles induces autophagy in macrophages. Int J Pharm. 2012;422:495-503.

30. Kroemer G, Levine B. Autophagic cell death: the story of a misnomer. Nat Rev Mol Cell Biol. 2008;9:1004-10.

31. Debnath J, Baehrecke E, Kroemer G. Does autophagy contribute to cell death? Autophagy. 2005;1:66-74.

32. Eisenberg-Lerner A, Bialik S, Simon H-U. Life and death partners: apoptosis, autophagy and the cross-talk between them. Cell Death Differ. 2009;16:966-75.

33. Stern ST, Adiseshaiah PP, Crist RM. Autophagy and lysosomal dysfunction as emerging mechanisms of nanomaterial toxicity. Part Fibre Toxicol. 2012;9:20.

34. Klionsky DJ. Autophagy: from phenomenology to molecular understanding in less than a decade. Nat Rev Mol Cell Biol. 2007;8:931-7.

35. Sardiello M, Palmieri M, di Ronza A, Medina DL, Valenza M, Gennarino VA, Di Malta C, Donaudy F, Embrione V, Polishchuk RS, Banfi S, Parenti G, Cattaneo E, Ballabio A. A gene network regulating lysosomal biogenesis and function. Science. 2009;325:473-7.

36. Settembre C, Di Malta C, Polito VA, Garcia Arencibia M, Vetrini F, Erdin S, Erdin SU, Huynh T, Medina D, Colella P, Sardiello M, Rubinsztein DC, Ballabio A. TFEB links autophagy to lysosomal biogenesis. Science. 2011;332:1429-33.

37. Neibert KD, Maysinger D. Mechanisms of cellular adaptation to quantum dots - the role of glutathione and transcription factor EB. Nanotoxicology. 2012;6:249-62.

38. Song W, Lee SS, Savini M, Popp L, Colvin VL, Segatori L. Ceria nanoparticles stabilized by organic surface coatings activate the lysosomeautophagy system and enhance autophagic clearance. ACS Nano. 2014;8:10328-42

39. Li M, Khambu B, Zhang H, Kang J-H, Chen X, Chen D, Vollmer L, Liu P-Q, Vogt A, Yin X-M. Suppression of lysosome function induces autophagy via a feedback down-regulation of MTOR complex 1 (MTORC1) activity. J Biol Chem. 2013;288:35769-80.

40. Boland B, Kumar A, Lee S, Platt FM, Wegiel J, Yu WH, Nixon RA. Autophagy induction and autophagosome clearance in neurons: relationship to autophagic pathology in Alzheimer's disease. Neurobiol Dis. 2008;28:6926-37

41. Dehay B, Martinez-Vicente M, Caldwell G, Yue Z, Cookson M, Klein C, Vila M, Bezard E. Lysosomal impairment in Parkinson's disease. Mov Disord. 2013;28:725-32.

42. Fass E, Shvets E, Degani I, Hirschberg K, Elazar Z. Microtubules support production of starvation-induced autophagosomes but not their targeting and fusion with lysosomes. J Cell Dev Biol. 2006;281:36303-16. 
43. Yamamoto A, Tagawa Y, Yoshimori T, Moriyama Y, Masaki R, Tashiro Y. Bafilomycin A1 prevents maturation of autophagic vacuoles by inhibiting fusion between autophagosomes and lysosomes in rat hepatoma cell line, H-4-II-E cells. Cell Struct Funct. 1998;23:33-42.

44. Baltazar GC, Guha S, Lu W, Lim J, Boesze-Battaglia K, Laties AM, Tyagi P, Kompella UB, Mitchell CH. Acidic nanoparticles are trafficked to lysosomes and restore an acidic lysosomal $\mathrm{pH}$ and degradative function to compromised ARPE-19 cells. PLoS One. 2012;7:e49635.

45. Frolich E, Meindl C, Roblegg E, Ebner B, Absenger M, Pieber T. Action of polystyrene nanoparticles of different sizes on lysosomal function and integrity. Part Fibre Toxicol. 2012;12:26.

46. Johnson-Lyles DN, Peifley K, Lockett S, Neun BW, Hansen M, Clogston J, Stern ST, McNeil SE. Fullerenol cytotoxicity in kidney cells is associated with cytoskeleton disruption, autophagic vacuole accumulation, and mitochondrial dysfunction. Toxicol Appl Pharmacol. 2010;248:249-58.

47. Li W, Chen C, Ye C, Wei T, Zhao Y, Lao F, Chen Z, Meng H, Gao Y, Yuan $H$, Xing G, Zhao F, Chai Z, Zhang X, Yang F, Han D, Tang X, Zhang Y. The translocation of fullerenic nanoparticles into lysosome via the pathway of clathrin-mediated endocytosis. Nanotechnology. 2008;19:145102.

48. Loos C, Syrovets T, Musyanovych A, Mailänder V, Landfester K, Simmet T. Amino-functionalized nanoparticles as inhibitors of mTOR and inducers of cell cycle arrest in leukemia cells. Biomaterials. 2014;35:1944-53.

49. Thomas T, Majoros I, Kotlyar A, Mullen D, Holl M, Baker JJ. Cationic poly(amidoamine) dendrimer induces lysosomal apoptotic pathway at therapeutically relevant concentrations. Biomacromolecules. 2009;10:3207-14.

50. Settembre C, Zoncu R, Medina DL, Vetrini F, Erdin S, Erdin S, Huynh T, Ferron M, Karsenty G, Vellard MC, Facchinetti V, Sabatini DM, Ballabio A A lysosome-to-nucleus signalling mechanism senses and regulates the lysosome via mTOR and TFEB. EMBO J. 2012;31:1095-108.
51. Kohlschütter A, Schulz A. Towards understanding the neuronal ceroid lipofuscinoses. Brain Dev. 2009;31:499-502.

52. Song W, Wang F, Lotfi P, Sardiello M, Segatori L. 2-hydroxypropyl-betacyclodextrin promotes TFEB-mediated activation of autophagy: implications for therapy. J Biol Chem. 2014;289:10211-22.

53. Lieberman A, Puertollano R, Raben N, Slaugenhaupt S, Walkley S, Ballabio A. Autophagy in lysosomal storage disorders. Autophagy. 2012;8:719-30.

54. Chiu H-W, Xia T, Lee Y-H, Chen C-W, Tsai J-C, Wang Y-J. Cationic polystyrene nanospheres induce autophagic cell death through the induction of endoplasmic reticulum stress. Nanoscale. 2015;7:736-46.

55. Eskelinen E-L, Tanaka Y, Saftig P. At the acidic edge: emerging functions for lysosomal membrane proteins. Trends Cell Biol. 2003;13:137-45.

56. de Duve C. The lysosome turns fifty. Nat Cell Biol. 2005;7:847-9.

57. Boya P, Kroemer G. Lysosomal membrane permeabilization in cell death. Oncogene. 2008;27:6434-51.

58. Luzio J, Pryor P, Bright N. Lysosomes: fusion and function. Nat Rev Mol Cell Biol. 2007:8:622-32.

59. Mizushima N, Yoshimorim T, Levine B. Methods in mammalian autophagy research. Cell. 2010;140:313-26.

60. Jokerst J, Khademi C, Gambhir S. Intracellular aggregation of multimodal silica nanoparticles for ultrasound-guided stem cell implantation. Sci Transl Med. 2013;5:177ra35.

61. Denton D, Nicolson S, Kumar S. Cell death by autophagy: facts and apparent artefacts. Cell Death Differ. 2012;19:87-95.

62. Shen HM, Codogno P. Autophagic cell death Loch Ness monster or endangered species? Autophagy. 2011;7:457-65.

63. Xu A, Yao M, Xu G, Ying J, Ma W, Li B, Jin Y. A physical model for the size-dependent cellular uptake of nanoparticles modified with cationic surfactants. Int J Nanomed. 2012;7:3547-54.

\section{Submit your next manuscript to BioMed Central and we will help you at every step:}

- We accept pre-submission inquiries

- Our selector tool helps you to find the most relevant journal

- We provide round the clock customer support

- Convenient online submission

- Thorough peer review

- Inclusion in PubMed and all major indexing services

- Maximum visibility for your research

Submit your manuscript at www.biomedcentral.com/submit
C Biomed Central 